ORIGINAL ARTICLE

\title{
Evaluation of the implementation of the alert issued by the UK National Patient Safety Agency on the storage and handling of potassium chloride concentrate solution
}

\author{
A J Lankshear, T A Sheldon, K V Lowson, I S Watt, J Wright
}

Qual Saf Health Care 2005;14:196-201. doi: 10.1136/qshc.2004.011874

See end of article for authors' affiliations

Correspondence to: Dr A J Lankshear, Department of Health Sciences, SeebohmRowntree Building, University of York, York YO10 5DD, UK; al25@ york.ac.uk

Accepted for publication 5 April 2005

\begin{abstract}
Objectives: To assess the effectiveness of the response of NHS hospital trusts to an alert issued by the National Patient Safety Agency designed to limit the availability of concentrated potassium chloride in hospitals in England and Wales, and to determine the nature of any unintended consequences.

Design: Multi-method study involving interviews and a physical inspection of clinical areas.

Setting: 207 clinical areas in 20 randomly selected acute NHS trusts in England and Wales between 31

October 2002 and 31 January 2003.

Participants: Senior managers and ward based medical and nursing staff.

Main outcome measures: Degree of staff awareness of and compliance with the requirements of the national alert, withdrawal of concentrated potassium chloride solutions from non-critical areas, provision of pre-diluted alternatives, storage and recording in accordance with controlled drug legislation.

Results: All trusts required that potassium chloride concentrate be stored in a separate locked cupboard from common injectable diluents (100\% compliance). Unauthorised stocks of potassium chloride were found in five clinical areas not authorised by the trust ( $98 \%$ compliance). All trusts required documentation control of potassium chloride concentrate in clinical areas, but errors were recorded in 20 of the 207 clinical areas visited (90\% compliance). Of those interviewed, $78 \%$ of nurses and $30 \%$ of junior doctors were aware of the alert.

Conclusions: The NPSA alert was effective and resulted in rapid development and implementation of local policies to reduce the availability of concentrated potassium chloride solutions. The success is likely to be partly due to the nature of the proposed changes and it cannot be assumed that future alerts will be equally effective. Continued vigilance will be necessary to help sustain the changes.
\end{abstract}

after the publication of the alert by the NPSA, we were commissioned to evaluate its impact. The study aims were to examine the receipt, dissemination, and management of the alert and to assess the extent of compliance with its requirements. Data collection started 1 week after the date
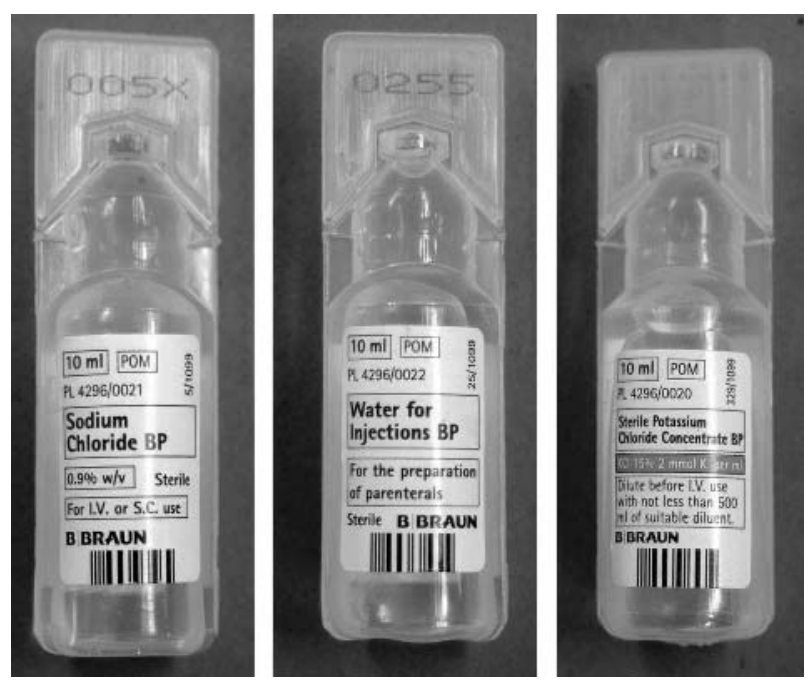

Figure 1 Plastic ampoules of sodium chloride, water for injection, and strong potassium chloride. Picture courtesy of Hull and East Yorkshire NHS Trust.
Given that this was the first directive from a new NHS organisation, it was important to study its effect so, 1 month 
Box 1 Requirements of the NPSA alert on potassium products

Potassium chloride $(\mathrm{KCl})$ concentrate solutions and other strong potassium solutions should be:

- restricted to intensive care environments;

- prepared in pharmacies when no commercial product of the correct concentration is available;

- subject to the same recording processes as controlled drugs;

- stored in a locked cupboard;

- signed for by a second practitioner;

- not transferred between clinical areas.

by which it was supposed to be implemented (31 October 2002) and was completed 3 months later.

\section{METHODS}

We planned to carry out this research in a random sample of 20 NHS hospital trusts. Forty NHS trusts were initially identified by applying computer generated random numbers to a Department of Health list of acute trusts. After taking mergers into account, the Chief Executives and Medical Directors of 37 trusts were invited to take part in two studies, the second of which (evaluation of the implementation of NICE guidance) entailed a detailed audit of patient records. ${ }^{8}$ Twenty trusts finally agreed to take part in both studies, the remainder citing as a reason the workload implications of the NICE study. The sample exhibited features of good geographical spread, size distribution, and performance rating (see Appendix 4 available online at http://www.qshc.com/ supplemental). The study was exempted from ethics approval by the South East MREC who classified it as an audit.

Semi-structured interview schedules for senior managers and structured schedules for ward staff were developed and administered by experienced nurse teachers from the University of York (see Appendices 1 and 2 available online at http://www.qshc.com/supplemental). Documentary evidence of action and consultation was collected to form an "audit trail". The same researchers also undertook an inspection of 10 clinical areas in each trust selected for the likelihood of regular potassium use.

\section{Interviews with senior managers}

All medical directors, clinical governance leads, chief pharmacists, chief nurses and clinical risk managers were approached for interview using a semi-structured format. We also interviewed others identified as having a key role in the dissemination and implementation process. Specific data were recorded on the interview schedules with these 70 senior managers to enable the development of descriptive statistics, but interviews were also recorded and transcribed.

Data analysis was concurrent and clear thematic categories and subcategories emerged. ${ }^{9} 10$ These categories were developed by two researchers working independently, and differences compared and reconciled by discussion. Differences between trusts and groups of respondents were examined using analytical matrices. ${ }^{1}$

\section{Ward audits}

Although the NPSA alert named some specific clinical areas that would require continued access to the concentrate, it also referred to "other specialist critical care areas" and it was found that most pharmacy departments held their own list of "authorised areas". In each trust at least five authorised and five unauthorised wards were visited and audited for availability, storage, and recording of potassium chloride using an audit checklist (see Appendix 3 available online at http://www.qshc.com/supplemental). Researchers inspected all drug cupboards, drug trolleys, other storage facilities, and preparation surfaces in both patient areas and in clinical preparation rooms. In addition, they examined opened boxes and containers holding sterile water and sodium chloride for injection and examined books used for recording the use of potassium. In total, 207 areas were inspected.

\section{Ward staff interviews}

A convenience sample of eight registered nurse ward managers and two junior doctors in each trust was interviewed to ascertain their awareness of the NPSA requirements and to explore any problems that had arisen since the implementation of the alert (see box 2 for definitions of staff types). In total, 166 ward managers (or their nominees) and 37 junior medical staff were interviewed in addition to 14 others including night nursing staff. A structured interview schedule was used for these interviews and these were coded and analysed using SPSS.

\section{Audit trail}

Trusts were asked to provide evidence of action taken in advance of and immediately following the alert. These dataconsisting of policies, memos and minutes of meetingswere used to triangulate the information given in the interviews.

\section{RESULTS}

The results reported here represent a distillation of data from all sources. The themes emerging from the senior manager interviews and the open questions in the structured interviews with ward staff related to previous action, dissemination, awareness and reaction, implementation of the guidance (storage, recording and authorisation), actual and potential unintended consequences and unresolved issues.

\section{Previous action taken}

Interviews with senior managers revealed that 19 trusts (95\%) had previously taken some prior action to reduce dependence on the concentrated solution although only one was fully compliant with all aspects of the guidance at the

\section{Box 2 Definitions of professional roles}

- Medical director: trust board member representing doctors

- Clinical governance lead: executive member of trust board with responsibility for clinical quality

- Ward manager/ward sister/charge nurse: registered nurse in charge of ward

- Junior doctor: all non-consultant grades

- Clinical risk manager: person responsible for undertaking risk assessments and identifying and addressing potential and actual clinical risk.

- House officer: newly qualified doctor in pre-registration year

- Senior house officer: registered doctor who has completed a minimum of 1 year's practice after qualifying. 
Table 1 Percentage of each staff group reached by stated means of communication

\begin{tabular}{|c|c|c|c|c|c|c|c|}
\hline Staff group & $\begin{array}{l}\text { Guidance/policy } \\
\text { circulated }\end{array}$ & Memo & Email & $\begin{array}{l}\text { Routine } \\
\text { meeting }\end{array}$ & $\begin{array}{l}\text { Orally by } \\
\text { pharmacist }\end{array}$ & Other & $\begin{array}{l}\text { Educational } \\
\text { event }\end{array}$ \\
\hline Ward sister/Charge nurse & $27.0 \%$ & $25.2 \%$ & $15.3 \%$ & $12.6 \%$ & $27.9 \%$ & $27.9 \%$ & $3.6 \%$ \\
\hline Staff nurse & $18.2 \%$ & $47.3 \%$ & $3.6 \%$ & $14.5 \%$ & $12.7 \%$ & $21.8 \%$ & $0.0 \%$ \\
\hline House officer & $5.6 \%$ & $61.1 \%$ & $0.0 \%$ & $5.6 \%$ & $5.6 \%$ & $50.0 \%$ & $5.6 \%$ \\
\hline $\mathrm{SHO}$ & $0.0 \%$ & $7.1 \%$ & $0.0 \%$ & $0.0 \%$ & $14.3 \%$ & $50.0 \%$ & $0.0 \%$ \\
\hline Specialist registrar & $20.0 \%$ & $0.0 \%$ & $20.0 \%$ & $20.0 \%$ & $20.0 \%$ & $40.0 \%$ & $0.0 \%$ \\
\hline Other & $50.0 \%$ & $28.6 \%$ & $28.6 \%$ & $21.4 \%$ & $21.4 \%$ & $21.4 \%$ & $0.0 \%$ \\
\hline
\end{tabular}

Figures do not sum to $100 \%$ as some respondents quoted more than one source of information.

time the alert was published. All managerial claims were substantiated by the audit trail.

\section{Dissemination, awareness, and reaction}

Interviews with ward based personnel revealed that an average of 135 nurses (79\%) and 11 doctors (30\%) were aware of the alert and could provide information concerning the provisions. Most nurses welcomed the action taken, typical comments being:

"It's not about making our jobs more difficult, it's about protecting us. It's been quite reassuring and improved safety. It recognises that we are humans and we do make mistakes." (Ward sister)

"The guidance has resulted in the benefit of having peace of mind." (Staff nurse)

There was considerable variation in the means by which nursing and medical staff at ward level had become aware of the policy or its provisions (table 1). Circulation of the policy, staff meetings, and oral communication by pharmacists appeared to be the most effective mechanisms for communicating with nursing staff, whilst memos, emails, and overheard conversations were the means by which most junior doctors had received the information. The ward interviews revealed that doctors were, almost without exception, unaware of any procedures relating to storage and recording of drugs or of obtaining them out of hours, claiming that these were nursing responsibilities.

\section{Authorisation of areas}

Four pharmacists reported having discussions with the NPSA to determine whether they could authorise theatres or paediatric units to hold the concentrated solution and had been told that this was possible, subject to a full risk assessment. The range in the number of areas authorised to hold the concentrate was 2-11 for small trusts; 4-11 for medium trusts, and 5-27 for large trusts.

Eighty seven of the 207 areas visited were found to be in possession of concentrated potassium chloride solution (table 2). Eighty two of these were named in trust policies as authorised. Of the five areas in three trusts that were not authorised, two (accident and emergency and renal unit) lay within the NPSA's definition of critical care areas and two were theatre recovery areas, which had been authorised in other trusts. Strong potassium chloride solution was found on only one general medical ward (from which it was promptly removed by the lead pharmacist) and no potassium phosphate was found outside intensive care units.

\section{Storage}

The audit revealed that, of the 87 wards and departments in which strong potassium chloride was found, in 70 cases it was stored in the controlled drug cupboard, in seven in the outer drug cupboard, and in 10 in a separate locked cupboard ( $100 \%$ compliance). Storage of potassium dihydrogen phosphate was also in line with the alert. Overall, it was clear that in the majority of areas the storage space for controlled drugs was inadequate for its purpose and, had potassium chloride been made a true controlled drug under the provisions of the act, many trusts would have required a wholesale replacement of these cupboards. As it is, in most wards these tiny cupboards are piled high with drugs, frequently necessitating the removal of several boxes to locate the drug required.

\section{Recording}

Fifty seven (65\%) of the areas in which the strong solution was found were recording its use in a controlled drug register and $25(29 \%)$ were using a separate potassium register. Five $(6 \%)$ were not making any record. The failure to record the use of strong potassium chloride was an error in four cases

Table 2 Wards audited indicating whether or not authorised to stock strong potassium chloride solution

\begin{tabular}{|c|c|c|c|c|c|}
\hline Wards and departments & $\begin{array}{l}\text { No of authorised } \\
\text { areas visited }\end{array}$ & $\begin{array}{l}\text { No of unauthorised } \\
\text { areas visited }\end{array}$ & Total visited & $\begin{array}{l}\mathrm{KCl} \text { found in } \\
\text { unauthorised area }\end{array}$ & $\begin{array}{l}\text { Recording error found } \\
\text { in at least one entry in } \\
\text { book }\end{array}$ \\
\hline Accident \& emergency & 5 & 5 & 10 & 1 & 4 \\
\hline Coronary care & 12 & 4 & 16 & & 1 \\
\hline High dependency & 6 & 4 & 10 & & 2 \\
\hline Intensive care & 28 & 1 & 29 & & 4 \\
\hline Medical & 2 & 53 & 55 & 1 & 1 \\
\hline Obstetrics & 3 & 2 & 5 & & 3 \\
\hline Paediatric & 5 & 6 & 11 & & \\
\hline Renal unit & 2 & 2 & 4 & 1 & \\
\hline Surgical & 0 & 35 & 35 & & 2 \\
\hline Special care baby unit & 10 & 0 & 10 & & \\
\hline Theatre - recovery & 7 & 6 & 13 & 2 & 2 \\
\hline Theatre - anaesthetics & 2 & 2 & 4 & & 1 \\
\hline Other & 0 & 5 & 5 & & \\
\hline Total & 82 & 125 & 207 & 5 & 20 \\
\hline
\end{tabular}


and a deliberate strategy in one intensive care area where the staff maintained that they already recorded and double signed the administration of potassium chloride in the patient's care plan and so refused to sign the controlled drug register for the preparation, citing pressure of time.

"The hardest bit of the guidance has been the double checking and signing for ... given that they already had to double sign the treatment card and double sign the label and what they were very concerned about was taking a one to one nurse away from a patient to go to a cupboard." (Clinical risk manager)

In addition to these five wards, auditors noted 13 cases in which second signatures were missing and two in which patients' names were not recorded.

\section{Out of hours arrangements}

No pharmacy in any of the 20 trusts visited was open for 24 hours. Typically, out of hours arrangements, as described by senior managers and confirmed by policy documents, indicated that the first action was to borrow a stronger commercially prepared solution from another ward area or, through the nurse in charge, to access these from an emergency drug cupboard. If these measures proved insufficient, the on-call pharmacist was to be contacted. In one trust the nurse in charge had authority to dispense with the on-call pharmacist in specific life threatening clinical emergencies, providing certain conditions were met.

\section{Actual and potential unintended consequences}

Senior managers were asked whether they had concerns about any unintended consequences of the implementation of the guidance. Five stated that there was a need to monitor whether restrictions were impeding access to potassium for patients who required it. This was of particular concern in cardiac theatres and cardiac intensive care units where potassium levels can fall quickly.

"In cardiac surgery you do actually use large volumes of potassium and some of it is actually not prescribed by doctors but perfusionists the people who drive the cardiopulmonary bypass. Their role includes putting potassium into the heart lung machine. In a way, cardiopulmonary perfusionists are practitioners in their own right and they have their own system of registration." (Consultant anaesthetist)

Concern was also expressed at the potential for deskilling staff in non-authorised areas, bearing in mind that all but four trusts retained the right to make the strong solution available for named patients on unauthorised areas. Some managers pointed out the need for constant vigilance lest the concentrate find its way back into unauthorised areas as a result of lack of storage space for, or non-availability of, commercially produced solutions or for reasons of cost or access. Finally, two were anxious about inappropriate use of the stronger solutions $(40 \mathrm{mmol}$ in $100 \mathrm{ml} ; 50 \mathrm{mmol}$ in 50 $\mathrm{ml}$ ) of which clinicians had no prior experience.

"There was a fear that we were changing the risk from the ampoules to the $40 \mathrm{mmol}$ in the $100 \mathrm{ml}$ bags. Firstly, they are unlicensed and, secondly, although not as concentrated as the injection, they can still cause harm so we had to demonstrate that we weren't merely transferring the risk from one preparation to another." (Chief pharmacist)

One pharmacist reported a recent case of a consultant giving the stronger solution as a bolus injection through a peripheral vein.

\section{Unresolved issues}

Both managers and ward staff were invited to comment on any issues arising from the alert and some of their responses have been embedded in sections above.

There had been a few recorded instances of problems encountered since the implementation of the guidance. Staff on paediatric and other wards with specific patient groups (cardiac surgery) were concerned about having to go through complex processes in the middle of the night to obtain the concentrate, although these were not common complaints.

"Fluid-restricted patients present a major challenge. The rigmarole to get hold of the concentrate in the middle of the night is ridiculous." (Ward sister)

There were also issues for manufacturers. Eighteen managers and ward staff stressed the need to address the packaging and labelling of ampoules and of IV solutions containing potassium to clearly differentiate them and so avoid confusion (fig l).

"After all that has been said about this, it is obscene that the ampoules are so similar to water and sodium chloride. You would have thought that they would have done something about it by now." (Registered nurse)

"The red writing on the IV bags is on the side of the bag. You need it on the front of bag in red." (Registered nurse)

Others stated that the sudden rise in demand for $40 \mathrm{mmol}$ potassium chloride in $100 \mathrm{ml}$ solutions of sodium chloride or glucose was creating problems for manufacturers and stressed the importance of these substances being constantly available.

"We had to wait three months for the glucose bags - there is no point in doing all this unless we can ensure a constant supply, otherwise people will go back." (Assistant chief pharmacist)

\section{DISCUSSION}

There are a number of limitations to this study. The 20 NHS trusts that agreed to take part may not be an unbiased sample even though the given reasons for non-participation were unrelated to the research study reported here. Trusts had around 6 weeks warning of our audit which may have prompted implementation of the alert, although in all cases the audit trail revealed activity from the date of the alert or earlier, rather than commencing after our first contact. Finally, the audit was carried out immediately after the implementation date and thus we may have failed to identify problems that had yet to surface, and conversely identified easily resolvable problems. The main strengths of the study lie in the physical inspection and audit trail which verified both the accuracy of interview data and the effectiveness of the management action.

Overall, the dissemination process from the NPSA to the trusts and thence to senior managers had worked well. The alert was welcomed by all pharmacists interviewed who felt that it had lent authority to their efforts to restrict the availability of concentrated ampoules and to promote the use of commercially available dilutions. This illustrates a potential value of these communications in providing strong central backing for the views of a significant professional group which may stimulate more action from senior managers than would otherwise be the case.

The list of areas permitted to stock potassium ampoules left trusts some room for manoeuvre and, on advice from the NPSA, most trusts had carried out a risk assessment and had added general theatres, labour wards, and paediatric wards to their list of authorised areas. There was wide variation in the number of wards authorised within trusts of the same size, which may indicate further room for removal of the concentrate from clinical areas.

The only opposition to the requirements of the alert came from intensive care staff, and particularly from those involved with cardiac surgery patients, who cited as a problem the time consuming nature of the new procedures caused by the location of some controlled drug cupboards and the fact that the drugs could only be checked out ampoule by ampoule to address the immediate need of the patient. 


\section{Key messages}

- The potentially fatal consequences of the inappropriate administration of concentrated potassium chloride have been acknowledged for many years.

- In 2002 the newly formed National Patient Safety Agency (NPSA) made the substance the subject of its first alert.

- All 20 trusts visited had taken action in response to the alert ( $100 \%$ compliance).

- The substance was found in five clinical areas which were not authorised by the trusts to stock it, although only one of these was a general ward $198 \%$ compliance).

- $78 \%$ of nurses and $30 \%$ of junior doctors were aware of the alert and could describe at least some of its requirements.

- Recording errors were found in 20 of the 207 areas visited (90\% compliance).

- Senior staff welcomed the intervention of the NPSA in assisting the implementation of a policy widely held to be in the interests of patient safety.

Given that the literature is peppered with tales of patient deaths arising from the confusion of potassium chloride with sodium chloride and water for injection, it seems inappropriate that the packaging and labelling has not been made more distinctive.

Poor awareness on the part of junior doctors, despite the commendable efforts of some pharmacists to communicate, was a source of concern. The numbers interviewed in this study are too small to justify recommendations in relation to this finding, nor did any of the senior manager respondents have any suggestions as to how to cope with this constantly changing resource. However, there may be strength in the prevailing view of the junior doctors that the management of drugs was purely the province of nursing staff. Nurses may both figuratively and literally "hold the key" to this problem and, if they are provided with prescribing guidance in relation to the administration of the potassium, they can challenge prescriptions that they perceive to be inappropriate.

Our research suggests that strong potassium chloride has been successfully removed from nearly all inappropriate clinical areas and there is reason for optimism that this may result in a marked reduction in sentinel events, as was reported in the US. ${ }^{72}$ The finding is compatible with those from the NPSA's "learning and sharing" initiative with trusts. $^{13}$

The rapid and comprehensive impact of the safety alert is likely to have been influenced by several factors that have been shown in the literature to influence the uptake of guidelines and other innovations. ${ }^{14-16}$ Most importantly in this context, the proposed change is strongly supported by evidence in the literature showing a clear advantage to patients, a factor recognised by the key players. Unlike many guidelines and efforts for behaviour change aimed at clinicians alone, the approach adopted by the alert led to action by senior management. This is vital, because change does not take place in isolation from the organisational context. ${ }^{16}$ The proposed changes were given strong backing by hospital pharmacists and by senior nurses and clinicians, who acted as opinion leaders and champions (though this by itself had not hitherto been sufficient to produce the change observed in this study). The safety alert was compatible with the shared norms and values of health professionals and was relatively simple to implement, in that no new skills were required, nor significant resources entailed. New directives such as that aimed at reducing the risk of wrong site surgery which are more complex and which also challenge professional styles, may prove more difficult to implement. For most staff there are likely to be few response barriers. However, the indifference of junior doctors suggests that sustaining the policy implementation may be challenging with some groups. Continuing vigilance of pharmacy departments, with annual random monitoring checks, may be required to ensure that ampoules do not effect a gradual return to unauthorised wards by prescription on a named patient basis. Cost, lack of storage space, inconsistent availability of some of the newer stronger solutions, and the difficulties in accessing concentrated potassium chloride out of hours may also contribute to its return.

\section{CONCLUSION}

The NPSA alert was effective, resulting in a rapid implantation of local policies to reduce the availability of concentrated potassium chloride solutions. The success is likely to be partly due to the nature of the proposed changes and future alerts may not be equally effective. Continued vigilance will be necessary to help sustain the changes.

\section{ACKNOWLEDGEMENTS}

The authors acknowledge the help of the following steering group members who are not authors: Professor N Cullum, Department of Health Sciences, University of York; Dr P West, Director, York Health Economics Consortium; and the audit team (Alison Foster-Lill, Celia Grant, Dawn Harrison, and David Stevenson).

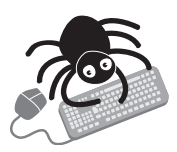

Appendices 1-4 are available online at $\mathrm{http}: / /$ www.qshc.com/supplemental

\section{Authors' affiliations}

A J Lankshear, T A Sheldon, I S Watt, Department of Health Sciences, University of York, UK

K V Lowson, York Health Economics Consortium, University of York, UK J Wright, Bradford Teaching Hospitals NHS Trust, Yorkshire, UK

This study was commissioned by the Patient Safety Research Programme. There were no competing interests. The full report can be located at: http://pcpoh.bham.ac.uk/publichealth/psrp/pdf/lankshear_kcl_final. pdf

\section{REFERENCES}

1 Department of Health. An organisation with a memory. London: Department of Health, 2000.

2 Department of Health. Building a safer NHS for patients. London: Department of Health, 2001

3 National Patient Safety Agency. Patient Safety Alert 23 July. London: National Patient Safety Agency, 2002

4 Joint Commission on Accreditation of Healthcare Organisations. Medication error prevention: potassium chloride: Sentinel Event Alert No 1, Joint Commission on Accreditation of Healthcare Organisations, 1998.

5 Australian Council for Safety and Quality in Healthcare Medication Safety Taskforce. Intravenous potassium chloride can be fatal if given inappropriately, Australian Council for Safety and Quality, 2003

6 Cousins DH, Upton DR. Medication error: lethal ampoules are still being issued. Pharmacy in Practice 1995;5:130-2.

7 Cohen M. Medication errors. Washington: American Pharmaceutical Association, 1999.

8 Sheldon TA, Cullum N, Dawson D, et al. What's the evidence that NICE guidance has been implemented? Results from a national evaluation using time series analysis audit of patient notes and interviews. BMJ 2004;329:999-1007.

9 Silverman D. Doing qualitative research: a practical handbook. London: Sage Publications, 2000.

10 Strauss A, Corbin J. Basics of qualitative research, 2nd ed. Thousand Oaks, California: Sage Publications, 1998. 
11 Miles M, Huberman A. Qualitative data analysis. London: Sage Publications, 1994

12 Joint Commission on Accreditation of Healthcare Organisations. Sentinel event statistics. Illinois: Joint Commission on Accreditation of Healthcare Organisations, 2004.

13 National Patient Safety Agency. Update on the implementation of recommended safety controls for potassium chloride in the NHS. London: National Patient Safety Agency, 2003.
14 NHS Centre for Research and Dissemination. Getting evidence into practice. Effective Health Care 1999;5(1):1-16.

15 Grimshaw JM, Thomas RE, MacLennan G, et al. Effectiveness and efficiency of guideline dissemination and implementation strategies. London: NHS Research \& Development HTA Programme, 2004.

16 Greenhalgh T, Robert G, MacFarlane F, et al. Diffusion of innovations in service organizations: systematic review and recommendations. Millbank $Q$ 2004;82:581-629

\section{Clinical Evidence-Call for contributors}

Clinical Evidence is a regularly updated evidence-based journal available worldwide both as a paper version and on the internet. Clinical Evidence needs to recruit a number of new contributors. Contributors are healthcare professionals or epidemiologists with experience in evidence-based medicine and the ability to write in a concise and structured way.

Areas for which we are currently seeking authors:

- Child health: nocturnal enuresis

- Eye disorders: bacterial conjunctivitis

- Male health: prostate cancer (metastatic)

- Women's health: pre-menstrual syndrome; pyelonephritis in non-pregnant women

However, we are always looking for others, so do not let this list discourage you.

Being a contributor involves:

- Selecting from a validated, screened search (performed by in-house Information Specialists) epidemiologically sound studies for inclusion.

- Documenting your decisions about which studies to include on an inclusion and exclusion form, which we keep on file.

- Writing the text to a highly structured template (about 1500-3000 words), using evidence from the final studies chosen, within 8-10 weeks of receiving the literature search.

- Working with Clinical Evidence editors to ensure that the final text meets epidemiological and style standards.

- Updating the text every six months using any new, sound evidence that becomes available. The Clinical Evidence in-house team will conduct the searches for contributors; your task is simply to filter out high quality studies and incorporate them in the existing text.

- To expand the topic to include a new question about once every 12-18 months.

If you would like to become a contributor for Clinical Evidence or require more information about what this involves please send your contact details and a copy of your CV, clearly stating the clinical area you are interested in, to Klara Brunnhuber (kbrunnhuber@ bmigroup.com).

\section{Call for peer reviewers}

Clinical Evidence also needs to recruit a number of new peer reviewers specifically with an interest in the clinical areas stated above, and also others related to general practice. Peer reviewers are healthcare professionals or epidemiologists with experience in evidence-based medicine. As a peer reviewer you would be asked for your views on the clinical relevance, validity, and accessibility of specific topics within the journal, and their usefulness to the intended audience (international generalists and healthcare professionals, possibly with limited statistical knowledge). Topics are usually 1500-3000 words in length and we would ask you to review between 2-5 topics per year. The peer review process takes place throughout the year, and our turnaround time for each review is ideally 10-14 days.

If you are interested in becoming a peer reviewer for Clinical Evidence, please complete the peer review questionnaire at www.clinicalevidence.com or contact Klara Brunnhuber (kbrunnhuber@bmigroup.com). 